\title{
South African Journal

\section{Competitiveness of the water utility consulting industry on the Internet in South Africa}

\author{
P. Rademeyer* \\ School of Information Technology, University of Pretoria \\ p.rademeyer@netgroup.co.za
}

\author{
M.M.M. Snyman \\ Department of Information Science, University of Pretoria \\ msnyman@postino.up.ac.za
}

* Author to whom correspondence should be addressed

\author{
Contents \\ 1. Introduction \\ 2. Competitiveness \\ 3. Water utility consulting industry \\ 4. Role of the Internet for competitiveness \\ 5. Porter's five competitive forces model \\ 6. Methodology \\ 7. Findings \\ 8. Conclusions and recommendations \\ 9. References
}

Key words: Competitiveness; Internet; Porter's five competitive forces model; water utility consulting industry

\section{Introduction}

Water is one of the key and probably the most fundamental and indispensable of the natural resources. It is essential to life, the environment, food production, hygiene, industry and power generation. The availability of water can also place a limit on economic growth and social development.

Water is a politically sensitive issue for the current South African government due to the perception that water is a key factor in social upliftment and development. The water industry in South Africa is faced with considerable challenges regarding the backlog of water services, potable water supply systems and sewage disposal systems, and the financial viability of local and municipal authorities. To address these needs, the government has enacted legislation pertaining to the water industry in South Africa, for example the National Water Act (No. 36 of 1998) and the Water Services Act (No. 108 of 1997). The first Act ensures that South Africa's water resources are protected, used, developed, conserved, managed and controlled in a sustainable and equitable manner, for the benefit of all people. The second Act created a developmental regulatory framework within which water services can be provided.

Owing to the changes in ways of providing water services, for example forming of water utilities, a number of opportunities have developed for the private sector. One such opportunity for the private sector in South Africa is to provide consulting services to water utility enterprises. These consulting services assist water utility enterprises to be more effective and efficient in their provision of services to the public. 
The aim of this article is to report on research done on the competitiveness of the water utility consulting industry on the Internet in South Africa. The study defines competitiveness, describes the water utility industry and the role of the Internet for competitiveness, and determines competitiveness within the water utility consulting industry by means of four of Porter's five competitive forces.

\section{Competitiveness}

Virtually all managers acknowledge the importance of understanding the industry they are functioning in, and their competitors. The United Kingdom (UK) Department of Trade and Industry (1998:online), indicates in its white paper Building the knowledge driven economy that competitiveness increasingly requires firms to build distinctive capabilities. This may reside in a brand name, research and development (R\&D) performance or in the tacit knowledge of an organization's employees. The white paper further implies that the quest for competitiveness increasingly needs to maintain, develop and utilise these knowledge assets.

Feurer and Chaharbaghi (1994:49) say that 'universal and exact definition for competitiveness does not exist', and therefore that competitiveness means different things to different enterprises. Some enterprises view competitiveness as the ability to persuade customers to choose their offerings over alternatives, whereas other enterprises view competitiveness as the ability to improve their process capabilities continuously. For the purposes of this article competitiveness is defined as the ability to persuade customers to choose one enterprise over alternatives.

To determine the way in which an enterprise can grow from its current competitive position to a new and stronger competitive position, a competitive strategy must be formulated. A competitive strategy is a broad formula of how an enterprise is going to compete, what its goals (also mission or objective) should be, and what policies will be needed to carry out those goals (Porter 1980:xvi). According to Porter (1980:xix), the questions as are set out in Figure 1, are essential to develop an optimal competitive strategy. This article will not address the issues of formulating a competitive strategy, but is focused on the second area 'What is happening in the environment?', and specifically on competitors and new entrants. It is important to keep in mind that it is often the early movers to structural change that can prosper, especially where existing competitors are slow to respond.

Figure 1 Process for formulating a competitive strategy (Porter 1980:xix)

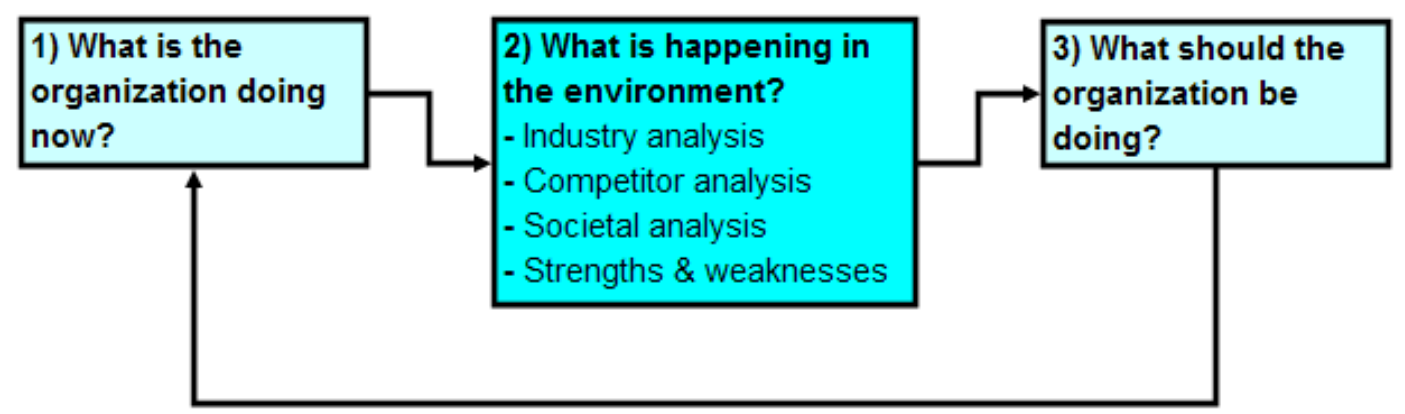

Currently, a wide variety of competitive analysis techniques are available, which have been developed for enterprises to understand their industries and their competitors. However, as pointed out by Prescott and Grant (1988:10), no single technique is sufficient for a complete analysis on competitiveness at an industry or enterprise level. Chang and Yeh (2001:405) add that although significant advances have been made in competitive analysis research, there is no best approach for the general competitiveness evaluation problem for a specific industry.

Porter's five competitive forces model is a well-known model in the competitiveness industry environment and was chosen as a tool for this research. The model will be discussed in more detail in section 5 of this article. 
To define the water utility consulting industry, it is important to firstly define the concepts utility and water utility.

A 'utility' is defined in the online dictionary, Dictionary.com (2003), as: 'An enterprise, subject to governmental regulation, that provides an essential commodity or service, such as water, electricity, transportation, or communication, to the public.'

A water utility enterprise focuses on delivering water-related services to the public. These services include the provisioning of potable water and/or the treatment and disposal of sewage. For the purpose of the research the focus was on the provision of water and not the treatment and disposal of sewage. The water utility enterprise delivers its services to the public by optimizing the following four main businesses:

- Capital investments. T his includes refurbishment projects and new capital projects of expansions.

- Asset management, operations and monitoring. This includes the management, operations and monitoring of assets like purification plants, treatment plants, reservoirs and pipe networks.

- Commercial operations and management. This includes the management and operations of revenue management systems, billing systems and customer relations systems.

- Business restructuring, market sector restructuring. This is the process of continuous alignment by the water utility enterprise to changes in government policies and regulations.

The water utility consulting industry consists of enterprises that provide services to water utilities enterprises in order to assist and advise the water utility enterprise to operate more effectively and efficiently by optimizing its business areas. Some areas where consulting services can be provided to water utility enterprises are, for example, civil engineering, mechanical engineering, electrical engineering, information technology, geographical information systems (GIS), revenue management, finance, human resources management, law and safety.

\section{Role of the Internet for competitiveness}

Buys (2000:11) points out that a few years ago nobody expected the development of a whole new borderless and electronic jurisdiction, commonly referred to as the Internet. He adds that irrespective of how we look at the Internet, the way people trade, communicate, entertain, research and educate will never be the same again.

The Internet is a valuable source of information, a way to communicate and a new way to do business. Therefore, the Internet, if used wisely, can be used by enterprises to expand their business and to become more competitive within their industry. The Internet can be used by enterprises in a variety of ways in order to improve competitiveness, for example by having a presence or Web site on the Internet with an accurate representation of the services they can render; by using Internet marketing agencies; and by subscribing to search engines to rank a Web site.

Since such a high volume of people use the Internet to search for information and to communicate, an individual or enterprise that advertises products or services on the Internet will have a competitive advantage above those that are not present on the Internet or did not correctly formulate the products or services they provide on the Internet. Currently more and more enterprises realise the importance of having an Internet presence in order to reach a much larger customer base. Using the Internet in this way can also stimulate the creativity of enterprises to advertise their services in such a way to persuade their customers to choose their products or services above alternatives.

The Internet is therefore a very valuable tool to be used by individuals or enterprises to search for products of services they require.

\section{Porter's five competitive forces model}

Porter's five competitive forces model for industry analysis is now a standard tool used both by academics and practitioners when conducting strategic management studies (Rugman and Verbeke 2000:377).

Porter (1980:xiv) presents a comprehensive framework of analytical techniques to help an enterprise analyse its industry as a whole, to predict the industry's future evolution, to understand its competitors and its own position, and to translate this analysis into a competitive strategy for a particular business. 
Porter (1980:3) indicates that the state of competition in an industry depends on five basic competitive forces, which are shown in Figure 2. The collective strength of these forces determines the ultimate profit potential in the industry, where profit potential is measured in terms of long-run return on invested capital.

\subsection{Porter's five competitive forces}

Porter (1980:4-34) describes the five competitive forces as follows:

- Industry competitors (rivalry among current competitors)

Rivalry among competitors refers to the competitive interplay between enterprises in the same industry. The degree of competitive rivalry is affected by factors such as strategy, differentiation, industry concentration, switching cost, and branding. Figure 2 indicates more factors that may influence competition. In most industries, especially when there are only a few major competitors, competition will very closely match the offering of others.

- Potential entrants (threat of new entrants)

Current competitors within an industry do not pose the only threat to enterprises. The possibility that new enterprises may enter the industry also affects competition. Factors within an industry that may limit or prohibit the entrance of new competitors are indicated in Figure 2.

Figure 2 Porter’s five competitive forces model, with industry factors that influence each force

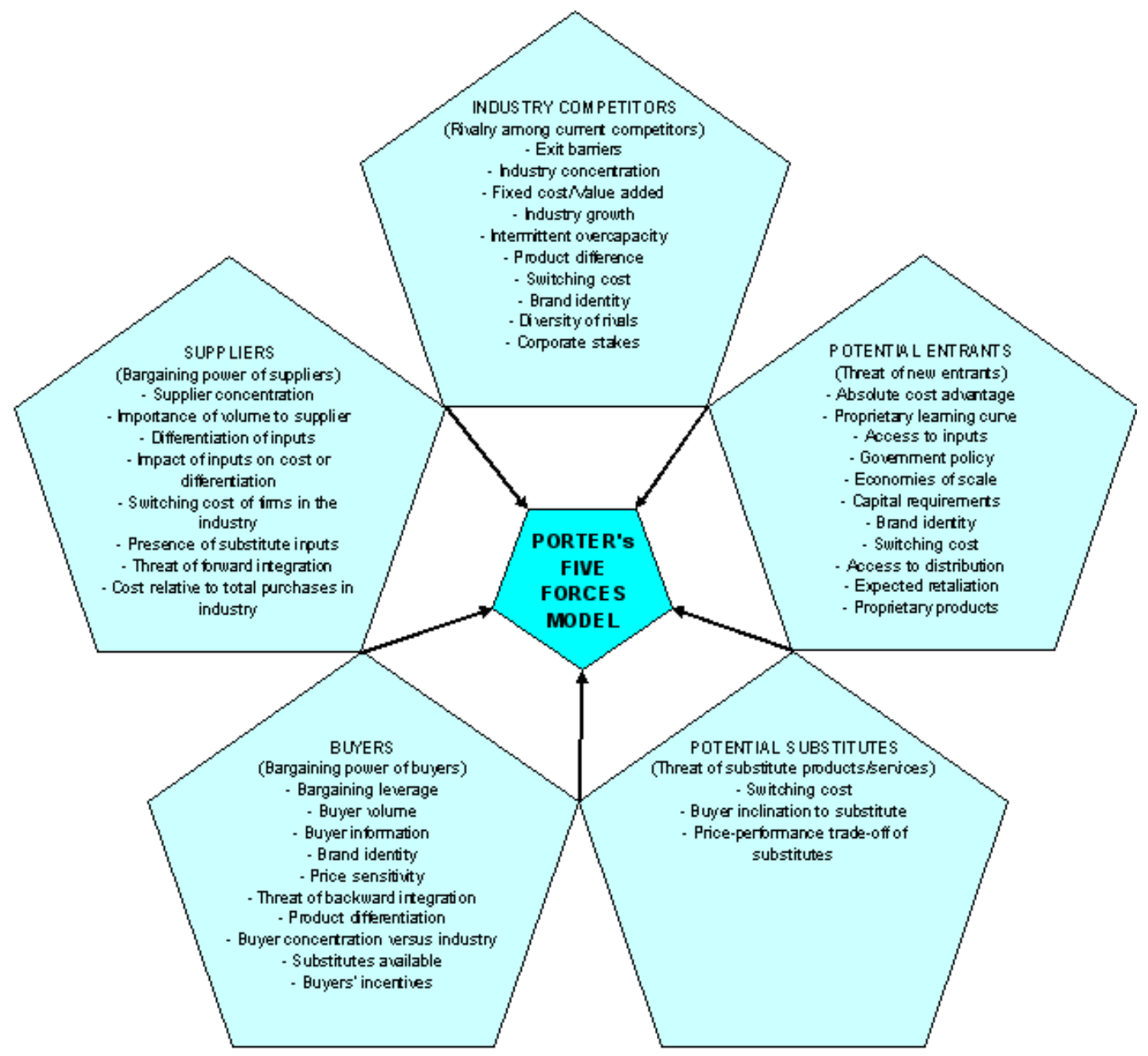

- Potential substitutes (threat of substitute products or services)

Potential substitutes are products, services or solutions that basically perform the same function, but are often based on a different process or technology. Depending on the level of abstraction nearly everything can be a substitution. Figure 2 indicates factors that may influence the force. 
Demand Econometrics (2003) states that the availability of products or services which buyers can select as acceptable substitution affects the health, growth and sustainability of industries.

- Buyers (bargaining power of buyers)

The bargaining power of buyers can force the competitors to lower their prices or force higher quality or better service, and therefore control the profitability of the industry. Factors that may influence this force can be seen in Figure 2.

- Suppliers (bargaining power of suppliers)

Suppliers can exert their bargaining power over participants by threatening to raise prices or reduce the quality. Some factors that may influence this force can be seen in Figure 2. A supplier group is powerful if it is more concentrated than the industry it sells to, or if the customer group is not important to the suppliers, or if the product is an important input to the buyer's business.

\subsection{Adaptation of Porter's five competitive forces}

Porter designed his five competitive forces model to be applied to an entire industry, as described above. However, the same analytical method can be used to study a narrower field of an industry, such as the presence of a specific industry on the Internet. Therefore, Porter's model can provide insight into both the online (Internet, databases, etc.), and offline competitiveness of an enterprise. For the purposes of this research the industry analysis was conducted by evaluating the presence of the water utility consulting industry on the Internet with regard to an adapted version of Porter's five competitive forces model. Only four of Porter's five forces were used for this research, namely: industry competitors, potential entrants, buyers and suppliers. The reason for excluding potential substitutes as a force was because it was not regarded as relevant to the study.

To determine how competitive the water utility consulting industry on the Internet in South Africa is, the selected four of Porter's five competitive forces were adapted in the following way in order to do an industry analysis:

- Industry competitors

Competitors were identified as consulting companies with an Internet presence that specify on their Web sites that they are providing consulting services to water utilities enterprises.

- Potential entrants

This force focused on the traditional civil engineering consulting enterprises doing work in the water field, that might potentially or were currently providing consulting services to water utilities enterprises, but did not have a presence on the Internet for publicizing their services to water utility enterprises.

- Buyers

Buyers were regarded as the water utility enterprises, which are the clients that need the services provided by the water utility consulting enterprises.

- Suppliers

For the purposes of the study suppliers were identified as enterprises that provide products or services to water utility consulting enterprises to assist them to be more effective and efficient in providing services to water utility enterprises.

\subsection{Data and strategy to populate Porter's model}

A comprehensive analysis of an industry and its competitors requires a great deal of data, some of them subtle and difficult to obtain (Porter 1980:XV). Porter (1980:368-369) also indicates that there are basically two types of data about an industry, namely published data (printed and electronic), and field data (data gathered from observers and interviews with industry participants). A comprehensive industry analysis is a massive task that can consume months if one is starting from scratch. For the purposes of the study, only published data on the Internet were evaluated and used in the adapted Porter's forces model. 


\section{Methodology}

\subsection{Data collection}

Information with regard to competitiveness, water utility enterprises and water utility consulting enterprises, the role of the Internet in obtaining a competitive advantage and Porter's five competitive forces was obtained from the literature.

To determine the competitiveness of the water utility consulting industry on the Internet in South Africa, information was obtained regarding the presence of these services on the Internet by using a South African search engine and the search phrase 'water utility'. Both Aardvark (http://aardvark.co.za) and Ananzi (http://www.ananzi.co.za) were considered. However, due to the limited number of hits on Ananzi (25 against the 228 of Aardvark) it was decided to make use of the Aardvark search engine.

A data sheet was also developed to capture relevant information. The data sheet was developed into two main sections, namely:

General hit information: this comprised the hit URL, South African hit, yes or no. South African Web sites had to be extracted in this way because the search engine had only two main options to search in, namely African Web sites, and globally. The Africa option was used. Thirdly, a Web site was indicated as applicable or not applicable. In this way it could be determined if the Web site would be evaluated or not. If the URL indicated that a Web site was from another country in Africa, it was marked as not applicable.

Porter's adapted four forces: The name of each relevant enterprise that was retrieved was entered under the appropriate force.

The South African Association of Consulting Engineers (SAACE) membership database that was available on the Internet was analysed to identify possible new entrants to the water utility consulting industry. Although various consulting engineering disciplines exist in the database, the following relevant engineering disciplines were chosen for this research due to the high demand for these services by water utilities enterprises to assist them to become more effective and efficient in providing water services to the public: civil engineering (CE) (water); facility/maintenance management (FM); information systems/technology (IT); and geographical information systems (GIS).

\subsection{Sampling and research process}

During the first level of investigation, only 174 of the 228 hits could be accessed through the Aardvark search engine. Each of the 174 hits was opened and evaluated. Of the 174 hits, 124 hits were South African Web sites, 45 hits were Web sites from African countries, excluding South Africa (e.g. Namibia, Zimbabwe, Uganda, Egypt) and five hits were URLs that were not operational and where access was denied.

During the second level of investigation the 124 South African Web sites were evaluated. Only 60 of the Web sites were applicable to this research indicating them as suitable to be evaluated and analysed according to Porter's adapted four forces. Of the 64 Web sites that were not applicable, 49 were general information articles that did not address a specific water utility enterprise. Fifteen of the unsuitable Web sites covered government and regulatory issues with regard to water utility and did not represent a specific water utility enterprise.

Therefore, of the 174 hits that were accessible through Aardvark, only 60 Web sites were applicable to the research, resulting in $34,5 \%$ usable information.

During the third level of investigation, the 60 applicable hits were evaluated and analysed and all duplicate enterprises eliminated. The following number of enterprises, hits, was identified for each of the four adapted competitive forces (see Figure 3):

- Competitors, 13 enterprises

- Potential entrants, 0 enterprise

- Buyers, 29 enterprises

- Suppliers, 6 enterprises

Figure 3 Hits representation of Porter's adapted four forces model 


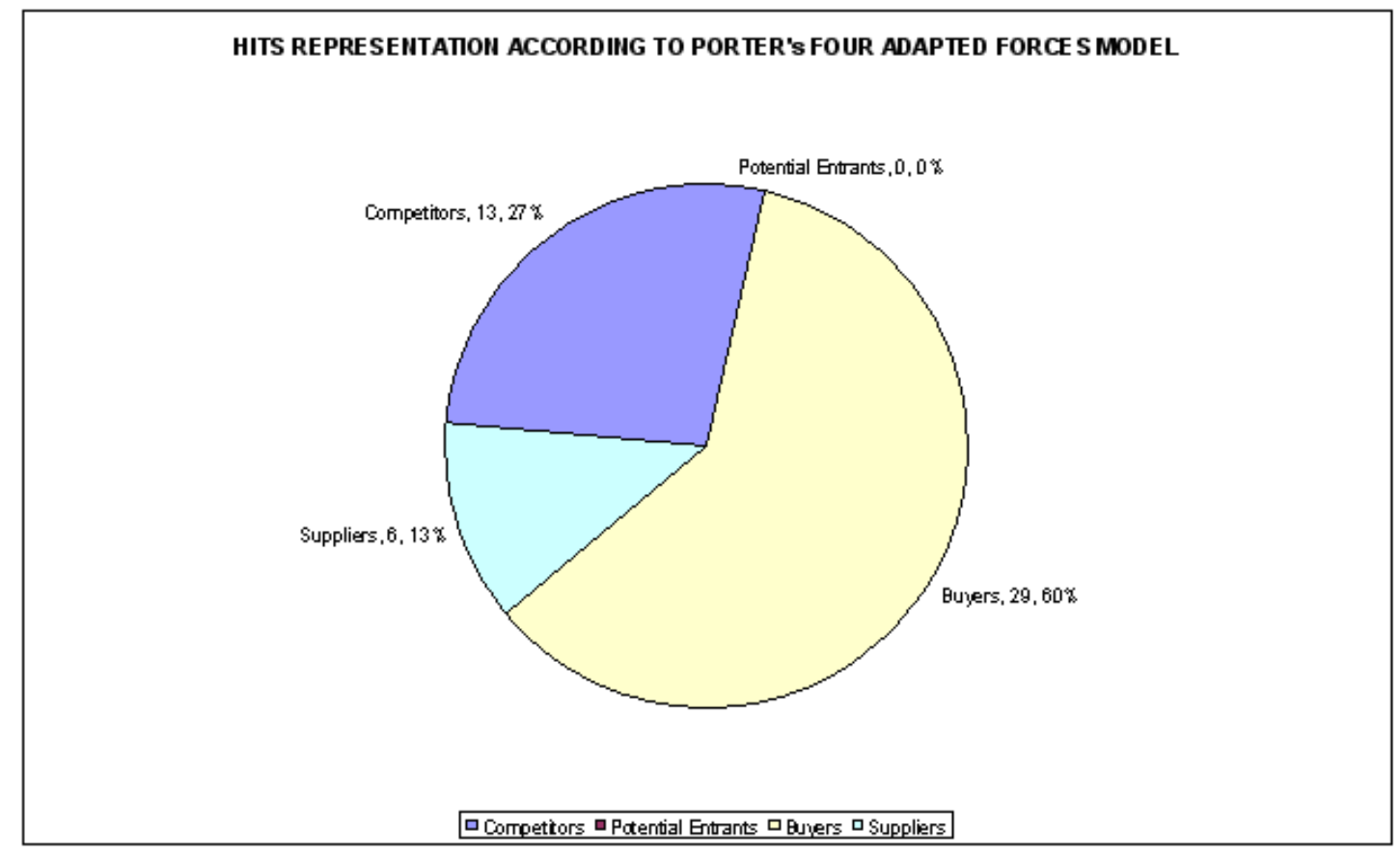

The 13 competitors that were identified on the Internet were then categorized according to the disciplines that were chosen from the SAACE database:

- Civil engineering (water), 1 enterprise

- Facility/maintenance management, 9 enterprises

- Information systems/technology, 3 enterprises

- Geographical information systems (GIS), 0 enterprises

From the four disciplines that were chosen from the SAACE database the following number of consulting engineering enterprises that provide expertise in these disciplines were identified:

- Civil engineering (all disciplines), 305 enterprises

- Facility/maintenance management (all disciplines), 74 enterprises

- Geographical information systems (all disciplines), 57 enterprises

- Information systems/technology (all disciplines), 44 enterprises

To determine which of the above-mentioned enterprises have a high capability to provide services to water utility enterprises and to market their services on the Internet, some additional analyses were performed. Four group comparisons were carried out of enterprises providing services in a combination of disciplines. Since most of the consulting services required by water utility enterprises need a great deal of civil engineering (CE) expertise in the water field, it was decided to analyse the combination of services that could be provided by these civil engineering (water) enterprises. This was done to determine which enterprises have a high potential to deliver services to water utility enterprises. The following results for each combination were obtained and are also illustrated in Figure 4:

- Combination 1: CE (water), FM, GIS, and IT, 10 enterprises

- Combination 2: CE (water), GIS, and IT, 5 enterprises

- Combination 3: CE (water), GIS, and FM, 5 enterprises

- Combination 4: CE (water), FM, and IT, 2 enterprises

Figure 4 Enterprises providing a combination of services 


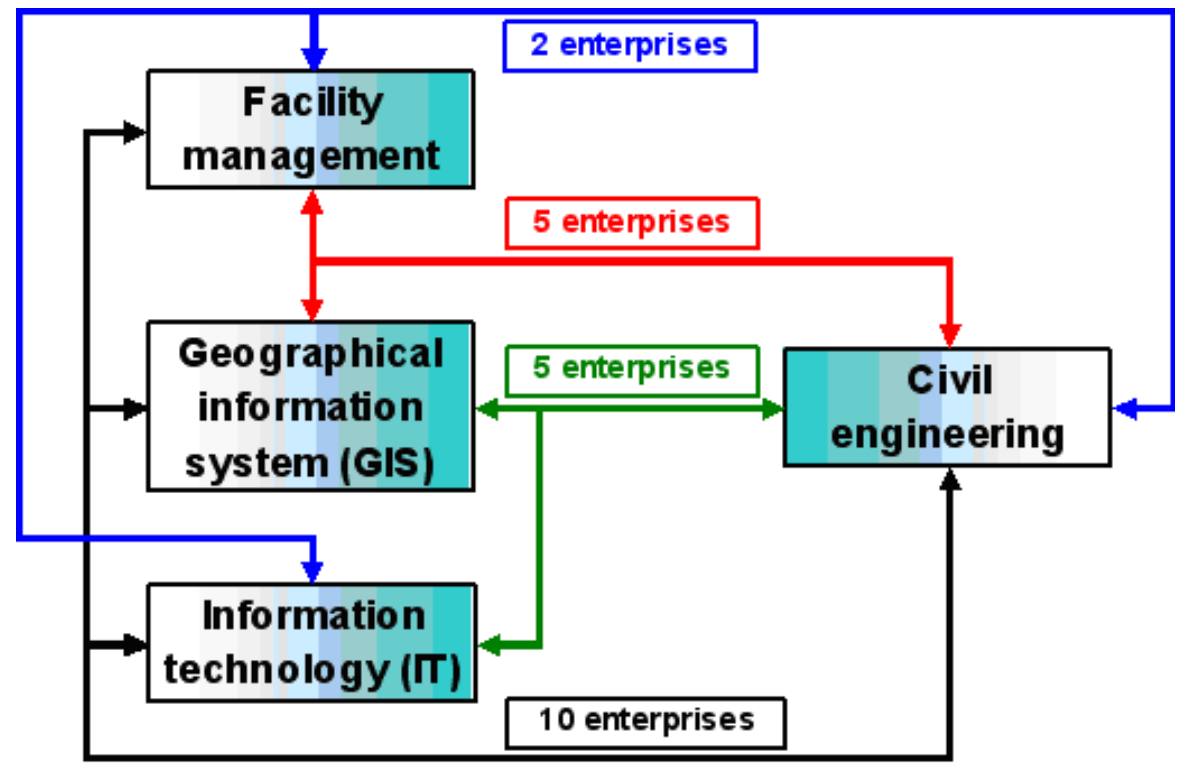

\section{Findings}

Of the 13 competitors identified (water utility consulting enterprises present on the Internet), only one competitor was also identified on the SAACE database. From the SAACE database and through the combination of services evaluation (see Figure 4) it was indicated that there were 22 enterprises that had a high potential to enter the water utility consulting industry on the Internet. If the one competitor that was present in both instances were eliminated, there would seem to be a possible 21 potential new entrants to the water utility consulting industry.

- With 13 competitors and 29 buyers identified on the Internet there was ample opportunity for new entrants to enter the market and rapidly gain market share on the Internet. This indicates that there were major opportunities for new entrants to advertise their services on the Internet.

- With regard to the six suppliers or enterprises delivering products or services to water utility consulting enterprises, there also seemed to be ample opportunity, especially if new entrants were going to enter the market, for these suppliers to expand their product line and services.

- From this research it can be seen that the competitiveness of the water utility consulting services industry on the Internet in South Africa was very low. This is due to the following reasons:

There were only 13 competitors (see Figure 3) advertising on the Internet that they were providing services to water utility enterprises.

In conjunction with the limited number of competitors, services were only rendered in three of the four disciplines identified for this research. Furthermore, no services were advertised on the Internet for all the other 'smaller' disciplines also required by the water utility enterprises.

Although there were competitors within the water utility consulting industry that provided services in a combination of disciplines, there was no water utility consulting enterprise on the Internet that provided services in a combination of disciplines. A competitor that offered a combination of services from a combination of disciplines would have a competitive advantage above the competitors only offering services in one discipline.

Through the evaluation and analysis of all consulting engineering enterprises registered on the SAACE database it became clear that there were a large number of consulting engineers that either had the potential to do work for water utilities, or were doing work for utilities due to the disciplines they provided services in, but that it was not reflected on their Web sites. For example, there are more than 300 civil engineering enterprises registered with SAACE in South Africa and only one of them was identified as a competitor on the Internet, which indicated that it provided services to water utilities enterprises. This indicates that major opportunities existed for civil engineering enterprises. 


\section{Conclusion and recommendations}

By using an adapted version of Michael E. Porter's five competitive forces model and by analysing the SAACE database of registered consulting engineering enterprises, it was determined that there currently seemed to be very little competitiveness in the water utility consulting industry on the Internet in South Africa. This could be seen from the very limited number of competitors that were advertising a limited number of services on the Internet.

The value of the Internet, specifically as an advertising tool, should never be underestimated by enterprises. It is therefore very important for enterprises that are providing products or services to advertise their products or services in great detail on the Internet and to specify the possible users, clients, of these products or services.

To improve the competitiveness of the water utility consulting industry on the Internet, industry players should:

- specifically indicate on the Internet that they provide services to water utility enterprises. The phrase 'water utility' or the words 'water' and 'utilities' should be used with the services that can be provided to water utility enterprises; and

- indicate all the services they can render to water utility enterprises. Specific emphasis should be placed on the combination of consulting services that can be provided to water utility enterprises to assist them to become more effective and efficient.

Those water utility consulting enterprises that implement these recommendations first will definitely have an immediate competitive advantage on the Internet above their competitors.

It should be mentioned that there are limitations with regard to this research and that the results should not be generalized. However, the findings of the study give an indication of the competitiveness or lack of it in the water utility consulting industry on the Internet in South Africa.

\section{References}

Buys, R. 2000. Cyberlaw @ South Africa: the law of the Internet in South Africa. Pretoria: Van Schaik.

Chang, Y-H and Yeh, C-H. 2001. Evaluating airline competitiveness using multi-attribute decision making. The International Journal of Management Science, 29:405-415.

Demand Econometrics. Porter's five forces model. [Online]. Available WWW:

http://drivedemand.com/logo.html (Accessed 15 August 2003).

Dictionary.com. [Online]. Available WWW: http://www.dictionary.com (Accessed 25 August 2003).

Feurer, R. and Chaharbaghi, K. 1994. Defining competitiveness: a holistic approach. Management Decision, 32(2):49-58

Porter, Michael E. 1980. Competitive strategy: techniques for analysing industries and competitors. New York: Free Press.

Prescott , J.E. and Grant J.H. 1988. A manager's guide for evaluating competitive analysis techniques. Interfaces, 18(3):10-22.

Rugman, A.M. and Verbeke, A. 2000. Six cases of corporate strategic responses to environmental regulations. European Management Journal. 18(4):377-385.

South Africa . 1997. Water Services Act. (Act No. 108 of 1997). [Online]. Available WWW: http://www.dwaf.gov.za/Documents/Default.asp?Legislation (Accessed 20 June 2003).

South Africa . 1998. National Water Act (Act No. 36 of 1998). [Online]. Available WWW: http://www.dwaf.gov.za/Documents/Default.asp?Legislation (Accessed 20 June 2003). 
http://www.saace.co.za (Accessed 15 August 2003).

United Kingdom . Department of Trade and Industry. 1998. Building the knowledge driven economy. [Online]. Available WWW: http://dti.gov.uk/comp/competitive/an_reprt.htm (Accessed 1 July 2003).

\section{Disclaimer}

Articles published in SAJIM are the opinions of the authors and do not necessarily reflect the opinion of the Editor, Board, Publisher, Webmaster or the Rand Afrikaans University. The user hereby waives any claim he/she/they may have or acquire against the publisher, its suppliers, licensees and sub licensees and indemnifies all said persons from any claims, lawsuits, proceedings, costs, special, incidental, consequential or indirect damages, including damages for loss of profits, loss of business or downtime arising out of or relating to the user's use of the Website. 
ISSN 1560-683X

Published by InterWord Communications for the Centre for Research in Web-based Applications,

Rand Afrikaans University 